\title{
Undoping Type of Highly Efficient Organic Light Emitting Diodes
}

\author{
Manabu Uchida, Youhei Ono, Hajime Yokoi, Takaharu Nakano, and \\ Kenji Furukawa \\ Yokohama Research Center, Chisso Corporation, \\ Ookawa, Kanazawa, Yokohama, Kanagawa 236-8605, Japan
}

\begin{abstract}
We have now prepared five boryl anthracene derivatives and evaluated them as an undoping type of emitting material for organic light emitting diodes (OLEDs). The derivatives had high glass transition temperatures because of a three dimensional molecular conformation of a dimesitylboryl anthracene. The OLEDs with the boryl anthracene derivatives showed high performance. For example, the efficiencies of green devices were over $15 \mathrm{ImW}^{-1}$ and the efficiency of a blue device reached $6.1 \mathrm{lmW}^{-1}$. The steric geometry of the boryl anthracene derivatives functions as an inhibitor of a intermolecular interaction. The longevity of an orange device had no problem for a practical use.
\end{abstract}

Keywords: OLED, undoping, emitting material, boryl anthracene

\section{Introduction}

Organic light emitting diodes (OLEDs) are candidates for the next generation flat panel displays. OLEDs, which are self-emitting devices, have some advantages such as easy fabrications and high efficiencies in contrast with devices with back lights such as LCDs. The efficiencies of OLEDs especially depend on emitting layers among few kinds of organic layers. Two types of emitting layers have been reported so far. One is an undoping type which is formed of a single fluorescent material with a high quantum yield of photoluminescence (PL) in solid state [1]. The other consists of a host with dopants which show high quantum yields in solution [2]. In the diode composed of small molecules, the latter has successfully been seen such as in the case of doping laser dyes in addition to phosphorescent dopants [3]. However, the latter has a disadvantage of the complication of the fabrication process because of mixing several organic materials. In the former, it is generally difficult to find emitting materials with the very high efficiency of PL in solid, due to a strong intermolecular interaction [4]. It is well known that the three dimensional (3-D) extension of molecules suppresses the interaction [5]. For instance, tris-(8-hydroxyquinoline)aluminum (Alq), which is a typical emitting material for OLEDs, has the stereochemical structure, in which Aluminum is spatially surrounded by quinoline units [6]. However, Alq is often used as a host compound with dopants because the photoluminescent efficiency of Alq is not so high in thin film. There have been many attempts to tailor the chemical structures of organic compounds in order to develop the high efficient emitting materials [7]. Our strategy for the development of undoping type emitting materials is to add the 3-D structure to a substituted anthracene with high quantum efficiency.

We chose a triarylborane framework as the basic structure taking into account the extended $\pi$ conjugation arisen from a specific property of a boron atom in addition to the geometry. There have been a few reports for triarylborane derivatives applied toward opto- and electrodevices [8]. The characteristics of OLEDs with thienyl borane derivatives have also been published [9]. They were firstly employed as electron transporting materials from the viewpoint of electron-accepting properties of dimesityl moieties and then developed into emitting materials by introducing triarylamine moieties with 
hole transporting properties. We expected that the combination of triarylborane and anthracene units would produce new undoping type of emitting materials. We herein report an application of boryl anthracene derivatives to emitting materials for OLEDs.

\section{Method}

2.1. Preparation of the present boryl anthracenes

The present boryl anthracene derivatives are shown in scheme 1.
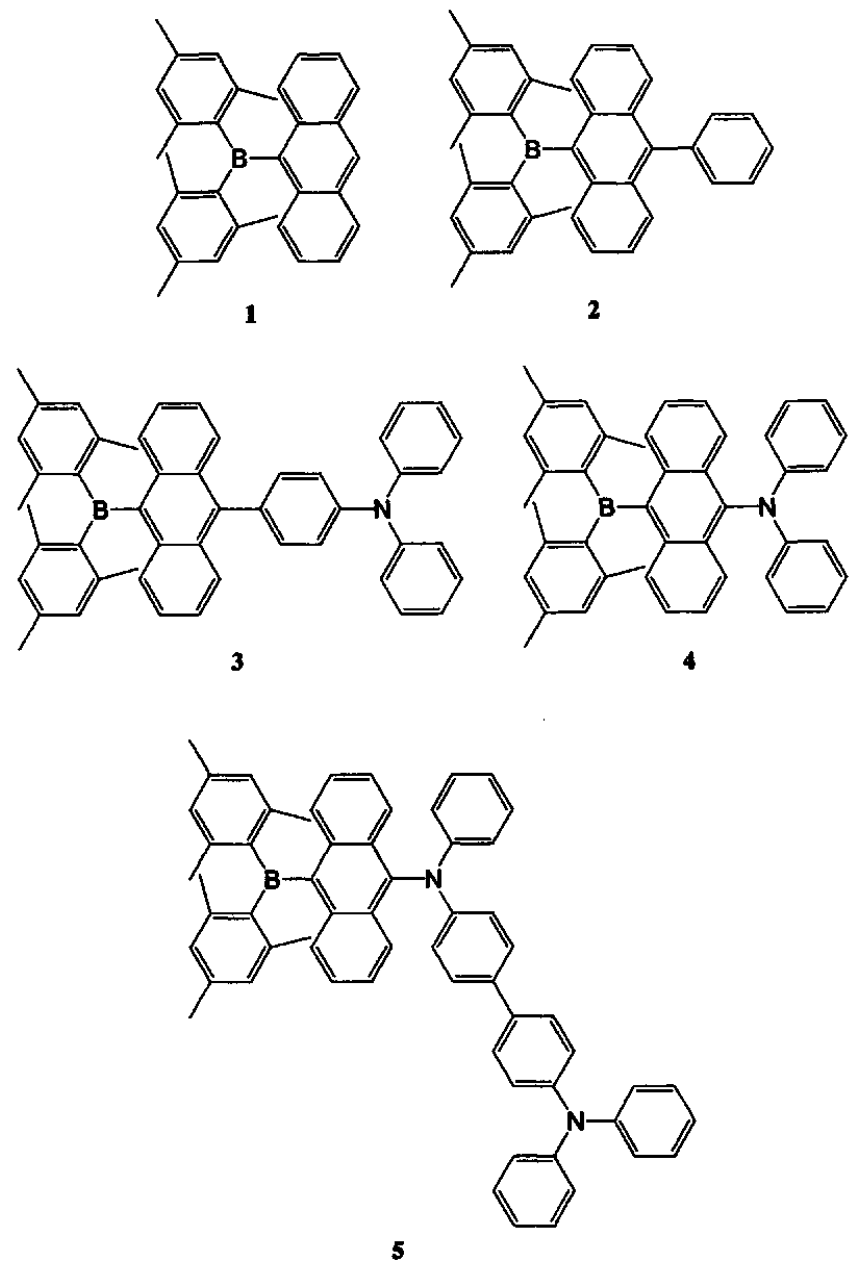

Scheme 1. The chemical structure of the boryl anthracene derivatives.

Compound 1 was prepared by the same method as described in the literature [10]. The new compounds 2 and 4 were also prepared by the same method as 1 except using respectively 9bromo-10-phenylanthracene and 9-bromo-10( $\mathrm{N}, \mathrm{N}$-diphenylamino)anthracene instead of 9 bromoanthracene.

9-Bromo-10-phenylanthracene was prepared by a bromination of 9-phenylanthracene: ${ }^{1} \mathrm{H}$ NMR $\left(\mathrm{CDCl}_{3}\right) \delta$ 8.60-8.62 (m, 2H), 7.56-7.66(m, 7H),
7.39-7.42 (m, 4H).

9-Bromo-10-(N,N-diphenylamino)anthracene was prepared by a coupling reaction using Pd catalyst between 9,10-dibromoanthracene and diphenylamine (see ref. [11] as regards the synthetic method): ${ }^{1} \mathrm{H}$ NMR $\left(\mathrm{CDCl}_{3}\right) \delta 8.62$ (d, $J=$ $8.8 \mathrm{~Hz}, 2 \mathrm{H}), 8.17(\mathrm{~d}, J=8.8 \mathrm{~Hz}, 2 \mathrm{H}), 7.57-7.61(\mathrm{~m}$, 2H), 7.43-7.45 (m, 2H), 7.15-7.19 (m, 4H), 7.05$7.08(\mathrm{~m}, 4 \mathrm{H}), 6.87-6.91(\mathrm{~m}, 2 \mathrm{H})$.

2: Yield $22 \%$. ${ }^{1} \mathrm{H}$ NMR $\left(\mathrm{CDCl}_{3}\right) \delta 8.11$ (dd, $J$ $=8.4$ and $1.2 \mathrm{~Hz}, 2 \mathrm{H}), 7.51-7.64(\mathrm{~m}, 5 \mathrm{H}), 7.43-$ 7.7.46 (m, 2H), 7.17-7.25 (m, 4H), 6.85 (br, $2 \mathrm{H})$, $6.68(\mathrm{br}, 2 \mathrm{H}), 2.28(\mathrm{~s}, 6 \mathrm{H}), 2.18(\mathrm{br}, 6 \mathrm{H}), 1.68(\mathrm{br}$, 6H). ${ }^{13} \mathrm{C} \mathrm{NMR}\left(\mathrm{CDCl}_{3}\right) \delta 139.9,139.8,139.4$, $133.6,131.3,129.7,129.0,128.6,128.4,127.7$, 127.4, 124.8, 124.7, 23.4, 21.2.

4: Yield $34 \%$. ${ }^{1} \mathrm{H}$ NMR $\left(\mathrm{CDCl}_{3}\right) \delta 8.13(\mathrm{~d}$, $J=8.4 \mathrm{~Hz}, 2 \mathrm{H}), 8.09(\mathrm{~d}, J=8.8 \mathrm{~Hz}, 2 \mathrm{H}), 7.25$ $7.30(\mathrm{~m}, 2 \mathrm{H}), 7.14-7.20(\mathrm{~m}, 6 \mathrm{H}), 7.07-7.10(\mathrm{~m}$, $4 \mathrm{H}), 6.85-6.89(\mathrm{~m}, 4 \mathrm{H}), 6.66(\mathrm{br}, 2 \mathrm{H}), 2.28(\mathrm{~s}$, 6H), 2.19 (br, 6H), 1.68 (br, 6H). ${ }^{13} \mathrm{C}$ NMR $\left(\mathrm{CDCl}_{3}\right) \delta$ 147.6, 140.0, 139.4, 135.1, 130.1, 129.2, $129.12,129.10,126.3,125.2,124.9,121.2,120.1$, 23.5, 21.2.

The other boryl anthracene derivatives 3 and 5 were prepared as follows.

3: To a $20 \mathrm{ml}$ THF solution of 4-bromo-N,Ndiphenylaniline $(1.94 \mathrm{~g}, 6 \mathrm{mmol})$ was dropwise added an $\mathrm{n}$-BuLi solution $\left(7.2 \mathrm{mmol}, 1.5 \mathrm{moll}^{-1}\right.$ hexane solution) at $-78{ }^{\circ} \mathrm{C}$. The mixture was stirred for $30 \mathrm{~min}$. $\mathrm{A} \mathrm{ZnCl}_{2}$ (tmen) $(1.80 \mathrm{~g}, 7.2$ mmol) was added as a solid and stirred for $1 \mathrm{~h}$ at room temperature. A 9-bromo-10(dimesitylboryl)anthracene $(3.0 \mathrm{~g}, 6 \mathrm{mmol})$ (prepared from the reaction between a dimesitylborylfluoride and a mono-lithium salt of 9,10-dibromoanthracene) and a dichlorobis(triphenylphosphine)palladium $\quad\left(\begin{array}{llll}0.14 & \mathrm{~g}, & 0.2\end{array}\right.$ mmol)were added as solids. The mixture was refluxed with stirring for $2 \mathrm{~h}$. Water was added to the mixture, followed by extraction with chloroform. The extract was washed with water, dried over $\mathrm{MgSO}_{4}$ and concentrated. A silica gel column chromatography (n-heptane/toluene $=5 / 1$, $R_{\mathrm{f}}=0.3$ ) followed by sublimation under high vacuum and recrystallization from an EtOAc gave $0.88 \mathrm{~g}(8.46 \mathrm{mmol})$ of pure 3 in $22 \%$ yield as a yellow solid: ${ }^{1} \mathrm{H}$ NMR $\left(\mathrm{CDCl}_{3}\right) \delta 8.12(\mathrm{~d}, J=8.8$ $\mathrm{Hz}, 2 \mathrm{H}$ ), 7.80 (dd, $J=8.4$ and $0.8 \mathrm{~Hz}, 2 \mathrm{H}$ ), 7.18$7.36(\mathrm{~m}, 16 \mathrm{H}), 7.06-7.10(\mathrm{~m}, 2 \mathrm{H}), 6.86(\mathrm{br}, 2 \mathrm{H})$, $6.68(\mathrm{br}, 2 \mathrm{H}), 2.28(\mathrm{~s}, 6 \mathrm{H}), 2.18(\mathrm{br}, 6 \mathrm{H}), 1.69$ (br, 6H). ${ }^{13} \mathrm{C} \mathrm{NMR}\left(\mathrm{CDCl}_{3}\right) \delta 147.9,147.1,139.8$, $139.7,133.7,133.0,132.2,129.9,129.4,129.0$, 128.6, 127.8, 124.8, 124.7, 123.1, 23.4, 21.2. 
5: A mixture of an aniline (2.14g $23 \mathrm{mmol})$, a 9-bromo-10-(dimesitylboryl)anthracene $(9.50 \mathrm{~g}, 19$ mmol), a sodium tert-butoxide $(2.20 \mathrm{~g}, 23 \mathrm{mmol})$, a $\mathrm{Pd}(\mathrm{dba})_{2} \quad(0.03 \mathrm{~g}, \quad 0.05 \mathrm{mmol})$ and a tris(tertbutyl)phosphine $(0.04 \mathrm{~g}, 0.2 \mathrm{mmol})$ in $60 \mathrm{ml}$ of xylene was heated with stirring at $125^{\circ} \mathrm{C}$ for $3 \mathrm{~h}$. Water was added to the mixture, followed by extraction with an EtOAc. The extract was washed with water, dried over $\mathrm{MgSO}_{4}$ and concentrated. A silica gel column chromatography (toluene) followed by recrystallization from a toluene gave $7.10 \mathrm{~g}$ (14 mmol) of pure $\mathrm{N}$-(10-dimesitylboryl-anthracen-9yl)aniline, 6 , in $74 \%$ yield: ${ }^{1} \mathrm{H}$ NMR $\left(\mathrm{CDCl}_{3}\right) \delta$ $8.22(\mathrm{~d}, J=8.0 \mathrm{~Hz}, 2 \mathrm{H}), 8.11(\mathrm{~d}, \mathrm{~J}=8.8 \mathrm{~Hz}, 2 \mathrm{H})$, 7.14-7.37 (m, 6H), 6.60-7.00 (m, 7H), 6.15 (br, 1H), 2.29 (s, 6H), 2.19 (br, 6H), 1.67 (br, 6H).

A 4-(4'-bromophenyl)triphenylamine $(4.8 \mathrm{~g}, 12$ mmol), $6(6.0 \mathrm{~g}, 12 \mathrm{mmol})$, a sodium tert-butoxide $(1.40 \mathrm{~g}, 14.4 \mathrm{mmol})$, a palladium acetate $(0.03 \mathrm{~g}$, $0.12 \mathrm{mmol}$ ) and a tris(tert-butyl)phosphine $(0.10 \mathrm{~g}$, $0.5 \mathrm{mmol}$ ) in $150 \mathrm{ml}$ of xylene was heated with stirring at $150^{\circ} \mathrm{C}$ for $2 \mathrm{~h}$. Water was added to the mixture, followed by extraction with an EtOAc. The extract was washed with water, dried over $\mathrm{MgSO}_{4}$ and concentrated. A silica gel column chromatography (n-heptane/toluene $=5 / 1, R_{\mathrm{f}}=0.4$ ) followed by recrystallization from an EtOAc gave $4.72 \mathrm{~g}(5.6 \mathrm{mmol})$ of pure 5 in $47 \%$ yield: ${ }^{1} \mathrm{H}$ $\operatorname{NMR}\left(\mathrm{CDCl}_{3}\right) \delta 8.15(\mathrm{~d}, J=8.4 \mathrm{~Hz}, 2 \mathrm{H}), 8.10$ (d, $J=8.8 \mathrm{~Hz}, 2 \mathrm{H}), 7.38(\mathrm{t}, J=8.4 \mathrm{~Hz}, 4 \mathrm{H}), 7.07-7.31$ $(\mathrm{m}, 20 \mathrm{H}), 7.00(\mathrm{t}, J=8.0 \mathrm{~Hz}, 2 \mathrm{H}), 6.88-6.91(\mathrm{~m}$, $3 \mathrm{H}), 6.67$ (br, 2H), 2.28 (s, 6H), 2.20 (br, 6H), 1.69 (br, 6H). ${ }^{13} \mathrm{C} \mathrm{NMR}\left(\mathrm{CDCl}_{3}\right) \delta 147.8,147.5,146.7$, $146.5,145.6,140.0,139.3,135.1,134.9,133.3$, $130.1,129.3,129.1,127.4,127.2,126.3,125.2$, $125.0,124.9,124.3,124.2,122.8,121.3,120.3$, 120.2, 23.5, 21.2.

For the application to the OLEDs, all products were further purified by distillation or sublimation under high vacuum $\left(1 \times 10^{-3} \mathrm{~Pa}\right)$.

\subsection{Fabrications of OLEDs}

The diode structure was as follows: ITO / NPB (50 nm) / emitting material (30 nm) / PyPySPyPy $(20 \mathrm{~nm}) / \mathrm{LiF}(0.5 \mathrm{~nm}) / \mathrm{Al}(100 \mathrm{~nm})$, where NPB is $\quad \mathrm{N}, \mathrm{N}^{\prime}$-di(1-naphthyl)-N,N'-diphenyl-4,4'benzidine and PyPySPyPy is 2,5-bis (6'-(2',2'bipyridyl))-1,1-dimethyl-3,4-diphenylsilole which is an electron transporting material developed in our laboratory [12]. All layers were formed by vacuum vapor deposition onto an ITO coated substrate at an ambient temperature. The active area defined by using a shadow mask was 5 X 5 $\mathrm{mm}^{2}$. All the measurements for $\mathrm{EL}$ characteristics were performed without any protection under an atmosphere.

2.3 Measurements of the physical properties and the EL characteristics

The thermal data were determined by using a Perkin Elmer UNIX-DSC7 differential scanning calorimeter. The ionization potentials (Ips) of boryl anthracenes in evaporated films were measured by RIKEN AC-1 under an atmosphere. The EL and PL spectra were measured with a HITACHI U-4010 fluorescence spectrophotometer. The luminance was measured with a TOPCOM BM-7 luminance meter. The power supply was controlled by using a personal computer and GP. IB. The light-current curve was measured with an ADVANTEST R6450 digital multimeter.

\section{Results}

\subsection{Physical properties of the boryl anthracenes}

The physical properties of the present boryl anthracene derivatives are summarized in table 1 . These compounds showed comparatively high glass transition temperatures (Tgs) due to the specific stereochemistry of a propeller configuration [10]. The $\mathrm{Tg}$ of the biggest molecule 5 reached $165^{\circ} \mathrm{C}$.

Table 1. The physical properties of the present boryl anthracenes in evaporated film.

\begin{tabular}{|c|c|c|c|c|c|}
\hline & $\mathrm{Tg} /{ }^{\circ} \mathrm{C}$ & $\begin{array}{l}\mathrm{PL} \\
\mathrm{nm}^{1)}\end{array}$ & $\mathrm{Ip} / \mathrm{eV}$ & $\begin{array}{l}\mathrm{Eg} \\
\mathrm{eV}^{2)}\end{array}$ & $\begin{array}{l}\mathrm{Ea} \\
\mathrm{eV}^{3)}\end{array}$ \\
\hline 1 & 83 & 452 & 6.05 & 2.73 & 3.32 \\
\hline 2 & 109 & 464 & 5.99 & 2.71 & 3.28 \\
\hline 3 & 147 & 506 & 5.78 & 2.60 & 3.18 \\
\hline 4 & 134 & 525 & 5.83 & 2.46 & 3.37 \\
\hline 5 & 165 & 584 & 5.51 & 2.36 & 3.15 \\
\hline
\end{tabular}

1) in toluene

2) determined from absorption spectra

3) $\mathrm{Ea}=\mathrm{Ip}-\mathrm{Eg}$

The maxima of their PLs in solution considerably depend on the substituents of an anthracene ring. For instance, compound 1, which does not have any substituent, compound 3 with a triphenyl amino group and compound 5 with the largest substituent showed PLs with maximum appearing at 452, 506 and $584 \mathrm{~nm}$, respectively. The color of emission could be tuned over a wide 




Figure 1. The L-J characteristics of the present OEL diodes with ITO / NPB / the boryl anthracenes / PyPySPyPy / LiF / Al: the boryl anthracenes, $1(\triangle), 2(+), 3(\bigcirc), 4(\nabla), 5(\square)$.

range from blue to red by the simple modification of the boryl anthracene 1. The extended $\pi$ conjugation through the boron atom resulted in making the PL peaks of the derivatives longer in comparison with the PL peak of anthracene. Furthermore, the amino substituted compounds 3, 4, and 5 showed the red shifts with regard to PL, which originate from a push-pull effect between an electron donating amino group and a boryl group with a high electron affinity. The variation of the PL peaks depending on the chemical structures of the boryl anthracene derivatives in toluene is consistent with that of energy gaps (Egs) in film.

The Ip values of the boryl anthracene derivatives were comparatively high because of an electron affinity of the dimesitylboryl group. The boryl anthracene derivatives with amino groups showed lower Ips than the derivatives in the absence of an amino group did.

3.2 Characteristics of EL with the boryl anthracenes

Table 2 indicates the luminescent properties of OLEDs having the present boryl anthracene derivatives as the undoping type of emitting materials. The peaks of the electroluminescent (EL) spectra in the diodes with the boryl

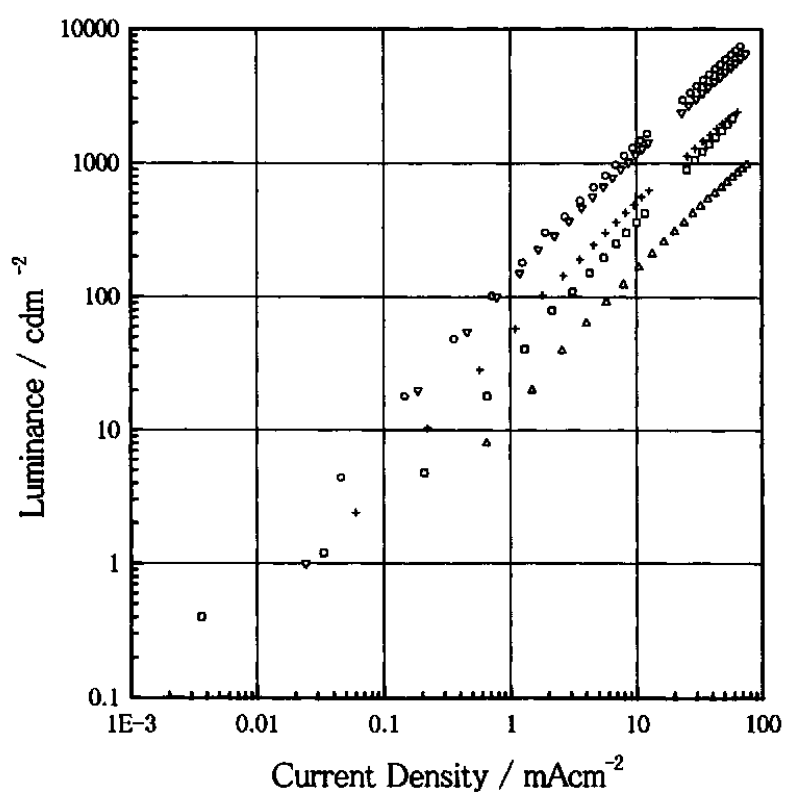

Figure 2. The J-V characteristics of the present OEL diodes with ITO / NPB / the boryl anthracenes / PyPySPyPy / LiF / Al: the boryl anthracenes, $1(\triangle), \mathbf{2}(+), \mathbf{3}(\bigcirc), \mathbf{4}(\nabla), \mathbf{5}(\square)$.

anthracene derivatives are almost consistent with the peaks of the PL spectra of the derivatives, respectively. But the EL spectrum of the diode with 1 showed a slight shoulder peak in the side of longer wavelength of the main peak. The height of shoulder peak and decreased with increasing the applied voltage.

Table 2. The characteristics of the OLEDs using the boryl anthracenes as emitting materials

\begin{tabular}{|c|c|c|c|}
\hline Emitting materials & $\begin{array}{l}\mathrm{EL} / \\
\mathrm{nm}\end{array}$ & $\begin{array}{l}\mathrm{PL} / \\
\mathrm{nm}^{1)}\end{array}$ & $\begin{array}{c}\text { CIE } \\
(\mathrm{x}, \mathrm{y})\end{array}$ \\
\hline 1 & 460 & 464 & $0.15,0.16^{2)}$ \\
\hline 2 & 477 & 479 & $0.17,0.31$ \\
\hline 3 & 511 & 513 & $0.24,0.58$ \\
\hline 4 & 532 & 535 & $0.34,0.63$ \\
\hline 5 & 580 & 577 & $0.52,0.48$ \\
\hline
\end{tabular}

1) in evaporated film

2) at $6 \mathrm{~V}$

Figure 1 shows the luminance-current density (L-J) characteristics of the diodes. The L-J efficiencies of these diodes were in the highest level among the diodes based on an undoped emitting layer. For example, the efficiency of the diode with 3 reached $14.3 \mathrm{cdA}^{-1}$. The diode with 
2 among bluer diodes had very high value of 5.9 $\mathrm{cdA}^{-1}$ as well.

The current density-voltage (J-V) characteristics of these diodes are shown in figure 2. The voltage required to start driving the diodes were at most $3 \mathrm{~V}$. The driving voltage of the diode with 5 was the lowest to obtain the luminance of a few $\mathrm{cdm}^{-2}$. The luminous efficiencies of green luminescent diodes with 2 or 3 reached $15.6 \mathrm{lmW}^{-1}$ at $100 \mathrm{cdm}^{-2}$.

The diode with 5 was tested for the durability at operating. The diode structure is as follows: ITO / HIL (40 nm) / NPB (10 nm) / 5 (30 nm) / PyPySPyPy $(20 \mathrm{~nm}) / \mathrm{LiF} / \mathrm{Al}$, where HIL represents a hole injecting layer. The operation carried out at the average current density of 50 $\mathrm{mAcm}{ }^{-2}$ and an initial luminance was $2348 \mathrm{cdm}^{-2}$. Even just after 120 hours, a luminance maintained $70 \%$ of the initial value.

\section{Discussion}

The boryl anthracene derivatives have high Tgs, as expected from results in NMR measurements. NMR spectra of all derivatives show the existence of steric isomers as shown in the method section. The chemical structures of the boryl anthracene derivatives are spatially extended so that the Tgs of the derivatives are very high.

The peaks of all EL spectra are in line with those of PL spectra, respectively. The boryl anthracene derivatives are difficult to make an exciplex with charge carrier transporting materials because of the steric conformation of the boryl anthracene. The shoulder peak shown in the diode with 1 seems to come from the electron transporting material, PyPySPyPy. The reason, why the diode with 1 have a shoulder peak depending on an applied voltage, is that the recombination site is near the electron transporting layer. It is considered that the energy transfer from an emitting material to an electron transporting material occurs due to a wide band gap of 1.

The characteristics of the OLEDs at $100 \mathrm{cdm}^{-2}$ are summarized in table 3 . The L-J efficiencies of the OLEDs showed very high value at each emission chromaticity coordinate, which is comparable to a doping type of diode. The high efficiencies in the OLEDs are reasonable to be given from the result of " $3-\mathrm{D}$ conformationization" of the boryl anthracene derivatives with high quantum efficiencies in solution.

Table 3. The characteristics of the OLEDs at the luminance of $100 \mathrm{cdm}^{-2}$

\begin{tabular}{|c|c|c|c|c|}
\hline $\begin{array}{c}\text { Emitting } \\
\text { materials }\end{array}$ & $\mathrm{V}$ & $\mathrm{mAcm}^{-2}$ & $\mathrm{cdA}^{-1}$ & $\mathrm{lmW}^{-1}$ \\
\hline 1 & 3.4 & 6.3 & 1.6 & 1.5 \\
\hline 2 & 3.0 & 1.7 & 5.9 & 6.1 \\
\hline 3 & 2.9 & 0.7 & 14.3 & 15.6 \\
\hline 4 & 2.6 & 0.8 & 12.5 & 15.7 \\
\hline 5 & 2.6 & 2.8 & 3.6 & 4.3 \\
\hline
\end{tabular}

The longevity evaluation of the diode including 5 and HIL is excellent for the application toward practical uses. Based on the relationship of inverse proportion between a half-life and an initial luminance, it is anticipated that the half-life of the diode can be about 10,000 hours under the initial luminance of $100 \mathrm{cdm}^{-2}$ [13].

\section{Conclusion}

It was shown that the boryl anthracene derivatives have high $\operatorname{Tgs}\left(83-165^{\circ} \mathrm{C}\right)$, various emission color (blue to orange) and high quantum yields of luminescence in solid state. These compounds have an excellent function as an undoping type of emitting material for OLEDs.

\section{Acknowledgement}

We would like to thank Professor K. Tamao and Dr. S. Yamaguchi of Kyoto University for many useful discussions.

\section{References}

1. (a) C. W. Tang, S. A. VanSlyke, Appl. Phys. Lett., 51 (1987) 913. (b) C. Adachi, S. Tokito, T. Tsutsui and S. Saito, Jpn. J. Appl. Phys., 27 (1988) L269. (c) C. Adachi, S. Tokito, T. Tsutsui and S. Saito, Jpn. J. Appl. Phys., 27 (1988) L713.

2. (a) C. W. Tang, S. A. VanSlyke and C. H. Chen, J. Appl. Phys., 65 (1989) 3610. (b) T. Wakimoto, Y. Yonemoto, J. Funaki, M. Tsuchida, R. Murayama, H. Nakada, H. Matsumoto, S. Yamamura and $M$. Nomura, Synth. Met., 91 (1997) 15. (c) Y. Sato, T. Ogata, S. Ichinosawa and Y. Murata, Synth. Met., 91 (1997) 103. (d) Y. Hamada, H. Kanno, T. Tsujioka, H. Takahashi and T. Usuki, Appl. Phys. Lett., 75 (1999) 1682. (e) C. Hosokawa, H. Higashi, 
H. Nakamura and T. Kusumoto, Appl. Phys. Lett., 67 (1995) 3853.

3. (a) M. A. Baldo, D. F. O'Brien, Y. You, A. Shoustikov, S. Sibley, M. E. Thompson and S. R. Forrest, Nature, 395 (1998) 151. (b) M. A. Baldo, S. Lamansky, P. E. Burrows, M. E. Thompson and S. R. Forrest, Appl. Phys. Lett., 75 (1999) 4.

4. N. Johansson, D. A. dos Santos, S. Guo, J. Cornil, M. Fahlman, J. Salbeck, H. Schenk, H. Arwin, J. L. Bredas and W. R. Salanek, J. Chem. Phys., 107 (1997) 2542 and references therein.

5. (a) J. Salbeck, N. Yu, J. Bauer, F. Weissortel and H. Bestgen, Synth. Met., 91 (1997) 209. (b) S. Tokito, K. Noda, K. Shimada, S.-i. Inoue, M. Kimura, Y. Sawaki and Y. Taga, Thin Solid Films, 363 (2000) 290. See also ref. 4.

6. S. R. Forrest, P. E. Burrows and M. E. Thompson, Organic Electroluminescent Materials and Devices, S. Miyata and H. S. Nalwa, Ed., Amsterdam (1997) 415.

7. (a) H. Tokailin, M. Matsuura, C. Hosokawa and T. Kusumoto, Proc. SPIE, 1910 (1993) 38. (b) J. Kido and Y. lizumi, Chem. Lett., (1997) 963. (c) J.
Su, T. Xu, K. Chen and H. Tian, Synth. Met., 91 (1997) 209. (d) H. Murata, G. G. Malliaras, M. Uchida, Y. Shen and Z. H. Kafafi submitted. See also refs 1,4 and 5 .

8. (a) Z. Yuan, N. J. Taylor, R. Ramachandran and T. B. Marder, Appl. Organomet. Chem., 10 (1996) 305. (b) N. Matsumi, K. Naka and Y. Chujo, J. Am. Chem. Soc., 120 (1998) 10776.

9. (a) T. Noda and Y. Shirota, J. Am. Chem. Soc., 120 (1998) 9714. (b) Y Shirota, M. Kinoshita, T. Noda, K. Okumoto and T. Ohara, J. Am. Chem. Soc., $122(2000) 11021$.

10. J. F. Blount, P. Finocchiaro, D. Gust, and $K$. Mislow, J. Am. Chem. Soc., 95 (1973) 7019.

11. B. H. Yang and S. L. Buchwald, J. Organomet. Chem., 576 (1999) 125.

12. M. Uchida, H. Yamada, H. Yokoi, T. Nakano and K. Furukawa, Proceedings of the $10^{\text {th }}$ International Workshop on Inorganic and Organic Electroluminescence, (2000) 241.

13. Y. Sato, S. Ichinosawa and H. Kanai, IEEE J. Selected Topics in Quantum Electronics, 4 (1998) 40. 